\title{
Sequential motor task (Luria's Fist-Edge-Palm Test) in children with benign focal epilepsy of childhood with centrotemporal spikes
}

\author{
Tarefa motora sequencial (Teste de Lúria punho-lado-palma) em crianças com epilepsia \\ focal benigna da infância com descarga centrotemporal

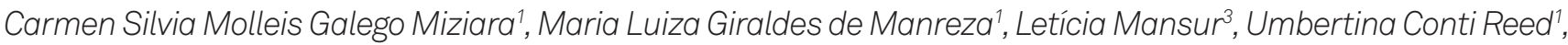 \\ Carlos Alberto Buchpiguel², Cooperação Interinstitucional de Apoio à Pesquisa sobre Cérebro Study Group
}

\begin{abstract}
This study evaluated the sequential motor manual actions in children with benign focal epilepsy of childhood with centrotemporal spikes (BECTS) and compares the results with matched control group, through the application of Luria's fist-edge-palm test. The children with BECTS underwent interictal single photon emission computed tomography (SPECT) and School Performance Test (SPT). Significant difference occurred between the study and control groups for manual motor action through three equal and three different movements. Children with lower school performance had higher error rate in the imitation of hand gestures. Another factor significantly associated with the failure was the abnormality in SPECT. Children with BECTS showed abnormalities in the test that evaluated manual motor programming/planning. This study may suggest that the functional changes related to epileptiform activity in rolandic region interfere with the executive function in children with BECTS.
\end{abstract}

Key words: epilepsy, rolandic, luria, executive function, learning.

\section{RESUMO}

Esse estudo avaliou ações motoras manuais sequenciais em crianças com epilepsia focal benigna da infância com descarga centrotemporal (EBICT) e comparou os resultados com o grupo controle pareado, através do teste de Lúria (punho-lado-palma). As crianças com EBICT realizaram single photon emission computed tomography (SPECT) interictal e Teste de Desempenho Escolar (TDE). Foram encontradas diferenças significativas entre os dois grupos nas atividades motoras de três movimentos iguais e três movimentos diferentes. As crianças com piores resultados no TDE e com SPECT alterado apresentaram mais erros no teste de imitação manual. Crianças com epilepsia fracassaram nos testes de avaliação motora que envolvem programação/planejamento. Esse estudo sugere que mudanças funcionais relacionadas à atividade epileptiforme na região rolândica interfere com as funções executivas de crianças com EBICT.

Palavras-Chave: epilepsia rolândica, lúria, função executiva, aprendizagem.

Benign focal epilepsy with centrotemporal discharge (BECTS) or rolandic epilepsy is the focal epilepsy most often seen in childhood ${ }^{1,2}$ and is not related to structural brain lesion $^{3}$, although focal characteristics are well established. The main feature of this epileptic syndrome is the occurrence of seizures involving the orofacial region and, less frequently, the upper limb $b^{4,5}$. Seizures tend to occur during sleep or near sleep ${ }^{6}$, with preservation of consciousness and motor or sensory manifestations, accompanied by intense drooling and inability to articulate words $s^{5,7}$. The duration of each event is usually very brief ${ }^{4,8.9}$, but can occur in clusters ${ }^{2}$. The highest incidence occurs between six and nine years old and predominantly in males $(2: 1)^{9.10}$. Seizures and electrographic manifestations disappear in adolescence without sequela.

\footnotetext{
Study carried out at Department of Neurology of School of Medicine of Universidade de São Paulo (USP), São Paulo SP, Brazil.

'Department of Neurology of School of Medicine of USP, São Paulo SP, Brazil;

${ }^{2}$ Department of Nuclear Medicine of School of Medicine of USP, São Paulo SP, Brazil;

${ }^{3}$ Department of Phonoaudilogy of School of Medicine of USP, São Paulo SP, Brazil.

Correspondence: Carmen Silvia Molleis Galego Miziara; Hospital das Clínicas of Medical School of USP, Neurology Department; Avenida Dr. Enéas de Carvalho Aguiar 255;05403-000 São Paulo SP - Brasil; E-mail:csmgm@uol.com.br

Support: Fundação de Amparo à Pesquisa do Estado de São Paulo (FAPESP) and Cooperação Interinstitucional de Apoio à Pesquisa sobre Cérebro (CInAPCE). Conflict of interest: There is no conflict of interest to declare.

Received 17 August 2012; Received in final form 26 September 2012; Accepted 03 October 2012.
} 
The electroencephalogram (EEG) tracing is quite peculiar, with intense activation because of drowsiness or sleep and, when awake, the protrusion of the tongue can suppress epileptiform activity. The epileptic discharge predominates over the centrotemporal region, but may involve nearby areas, such as the frontal and parietal regions ${ }^{2}$. The main feature of this activity is the wave morphology, consisting of sharp wave or spike followed by a slow wave of high amplitude with the background activity completely normal. Recent studies shown that children with BECTS may have cognitive disorders (attention, memory short-term, visuo-motor, learning, oral dyspraxia, and language $)^{3,11-15}$. The clinical symptoms of BECTS, as described by Lerman ${ }^{16}$, suggests that the source of the problem is in the lower rolandic cortex, representation of the face and throat, a fact corroborated by Holmes and Wong ${ }^{17}$. Failure in manual gestures test on command presented by children with BECTS can be explained by the interference of the epileptiform activity on brain areas responsible for programming and planning of movements or because the children had not yet acquired this skill (maturational development). The aim of this study was to evaluate the manual motor ability in children with BECTS and compare the result with the matched control group.

\section{METHODS}

Forty children with BECTS and 82 children without epilepsy (control group) were evaluated, and matched according to gender, age, and educational levels, through the application of Luria's fist-edge-palm test.

The children were requested to imitate as quickly as possible, sequenced movements with hands made by the examiner. This test was divided into two stages: a) with three identical movements (fist-fist-fist, edge-edge-edge, and palm-palm-palm), and b) with different movements (fistpalm-edge, fist-edge-palm, edge-palm-fist, edgefist-palm, and palm-fist-edge, palm-edge-fist). All test phases were explained by the examiner before each run. The perseveration of movements (perseveration an iterative repetition or continuation of an earlier response after the change request in the task) and inaccuracy in the execution sequence of movements after three attempts were consider failures. All children included in the study group underwent single photon emission computerized tomography (SPECT) in the intercritical period. Rotational type tomographic scintillation cameras were used for a wide field of view (Orbiter, Siemens, Hofman States, IL), which were coupled to dedicated image processors (Micro Delta, SIEMENS-Hofman States, IL), in the Nuclear Medicine Center, Department of Radiology, School of Medicine, Universidade de São Paulo (Laboratório de Investigação Médica - LIM-43). The topographic images were obtained 15 minutes after the intravenous administration of
$1110 \mathrm{MBq}$ (30 mCi) of ethylene-diylbis-L-cysteine diethyl ester dihydrochloride marked with technetium-99m (IPENCNEN, SP). Patients were positioned in line with the mental orbital perpendicular to the longitudinal tomographic litter. The images were processed using Butterworth filter in the frequency of 0.35 Nyquist order number 10 . Cuts of $3 \mathrm{~mm}$ thick were obtained in the transverse, coronal, and sagittal planes. All children in both the study and control groups were evaluated for academic performance through the implementation of the School Performance Test (SPT). The SPT was applied by the examiner without the presence of family or any other spectator. The child investigated was required only to perform subtests in sequence, starting with the writing, followed by questions of arithmetic, and lastly with reading; the child also determined the closure of the test. To obtain the total score, the three scores of the subtests were added. This total has been classified by grade level and age of the child.

Parents or guardians of children who participated in this study signed an informed consent form approved by the Ethics Committee for Analysis of Research Projects of the Hospital das Clínicas of the School of Medicine, USP, Brazil.

\section{RESULTS}

\section{Luria's fist-edge-palm task}

The evidence of three sequential movements whether repeated or not, showed that only three (7.5\%) children with BECTS were able to perform all the steps successfully, and one $(2.5 \%)$ did not complete any sequence correctly. The higher frequency of failure was detected in tests with three different movements in sequence: only six children (15\%) with BECTS performed the tests with no errors, whereas $24(29.62 \%)$ in the control completed all phases of the test (Tab 1).

All children in the study group were submitted to SPECT. Perfusion abnormalities, characterized by poor cerebral blood flow were observed in 12 children, except in one patient, who showed increased radiopharmaceutical concentration. The results were as follows: perfusion deficit in the right and left temporal region, the high concentration in the bilateral frontal

Table 1. Distribution of correct performance in the test with three different movements.

\begin{tabular}{lcc}
$\begin{array}{l}\text { Number } \\
\text { achievement }\end{array}$ & $\begin{array}{c}\text { Study group } \\
\mathrm{n}(\%)\end{array}$ & $\begin{array}{c}\text { Control group } \\
\mathrm{n}(\%)\end{array}$ \\
\hline 6 & $3(7.5)$ & $25(30.49)$ \\
5 & $16(40)$ & $26(31.70)$ \\
4 & $12(30)$ & $15(18.30)$ \\
3 & $3(7)$ & $11(13.41)$ \\
2 & $5(12)$ & $5(6.10)$ \\
1 & 0 & 0 \\
0 & $1(2.5)$ & 0 \\
Total & 40 & 82 \\
\hline
\end{tabular}


region, perfusion defects in left temporal lobe, perfusion defects in the left temporal region, perfusion defects in the mesial right, slight irregularity in the left temporal lobe, perfusion defects in the left temporal and at the mesial and polar anterior temporal lobe, perfusion deficit in the bilateral temporal, left perfusion defects, perfusion defects in the right temporal region. Eleven children showed hypoperfusion in the temporal region and one showed increased radiopharmaceutical concentration in the frontal region.

\section{School Performance Test}

The evaluation of school performance of children with BECTS by SPT showed that three patients (7.5\%) were classified as superior, $11(27.5 \%)$ as middle and 26 (65\%) as lower (Tab 2).

The statistical analysis showed that there was statistically significant difference between the study and control groups for the hand movements searched through 3 identical movements $(p=0.007)$ and 3 different movements $(p=0.027)$. Children who obtained the lowest results in the hand gestures imitation also had lower school performance $(p=0.021)$. Another factor associated with the highest failures in actions by imitation movement was the abnormality in SPECT $(p=0.011)$.

There was no statistically significant difference between the results of the Luria's fist-edge-palm task or SPT and those found on SPECT.

\section{DISCUSSION}

The voluntary movement (praxis) is a complex functional system that incorporates a number of conditions or factors that depend on the synchronous operation of an entire group of cortical and subcortical areas ${ }^{18}$. The presence of oral dyspraxia in children with BECTS suggests a dysfunction of the lower rolandic motor area brain regions involved in the planning or execution of complex movements not linguistic ${ }^{15}$; a few authors have also cited this region in their studies ${ }^{12,19}$. The evaluation of the sequential movement of the hands can be useful in the interpretation of the motor performance of children with BECTS and is useful for the evaluation of oral movement as both are linked to activation of the motor cortex. In 1992, Laub et al. ${ }^{20}$ evaluated nine children with BECTS through neuropsychological and language tests and correlated the results of these tests with SPECT. The final conclusion of the authors

Table 2. Distribution of School Performance Test results between the study and control groups.

\begin{tabular}{lcc} 
Classification & $\begin{array}{c}\text { Study group } \\
\mathrm{n}(\%)\end{array}$ & $\begin{array}{c}\text { Control group } \\
\mathrm{n}(\%)\end{array}$ \\
\hline Superior & $3(7.5)$ & $15(36.6)$ \\
Middle & $11(27.5)$ & $12(29.3)$ \\
Lower & $26(65)$ & $14(34.1)$ \\
\hline
\end{tabular}

is that there was no relationship between the findings and in the neuropsychological abnormalities in cerebral blood flow. Sarikaya et al. ${ }^{21}$ analyzed the SPECT abnormalities in epileptic children and observed an inverse correlation between the asymmetry index of cerebral blood flow with the child's age at the time of onset of seizures, and a positive correlation with the frequency of crises. According Duncan ${ }^{22}$, the correlation between the laterality of the epileptic discharge and hypoperfusion was quite variable. The fist-edge-palm task (FEPT) was described by Luria, in 1966. The principle was applied to assess voluntary movement disorders, however, their approach exceeded this goal. Its application enables the investigation of frontal lobe functions and thus can serve as a screening to assess executive function, especially on the evaluation of movements with sequential components, imitation, and inhibition $^{23,24}$. This test provides information about programming and planning of motor actions and the brain area involved in this production is the frontal region ${ }^{25}$. Currently, there are other brain areas, described as neural networks that are involved, including: bilateral sensorimotor area, supplementary motor area, left parietal cortex, and right cerebellum. There is no evidence of activation of the prefrontal area ${ }^{23}$. Ying et al. ${ }^{26}$ concluded that the prefrontal cortex acts indirectly on the evidence of movement sequences, as a regulator. Recent studies have demonstrated the great importance of the premotor cortex in the recognition of motor action, especially in the planning required for the execution of complex motor sequences integrated into the parietal lobe ${ }^{27,28}$. The extensive involvement of frontal structures in motor activity does not stop there. Broca's area, which for many years been closely associated with the language (speech), plays an important role in motor activity, mainly on the observation and execution of hand movements. Neuroimaging studies demonstrate activity of Broca's area during imitation ${ }^{29}$. As highlighted by Nitrini et al. ${ }^{30}$, the reproduction and the sequenced movements require visual and verbal strategies (semantic) and this explains the difficulties that illiterate people have when carrying out this test when compared with people with higher education levels. In our study, children with low school performance had greater frequency of failure in performing sequential movements with hands. This fact strengthens the direct relationship between schooling and performance of the Luria's fist-edge-palm task. A few authors report that a generalized impairment in imitation of manual gestures was noted, which is often found in conjunction with speech apraxia and may reflect disturbance of Broca's area, which also subserves action recognition. In this study, no child had dyspraxia of speech ${ }^{22,31,32}$. Although hemispheric asymmetry with regard to production and execution of movement is important, the left hemisphere is more important to carry out purposeful movements and the right for exploratory activity. Crary ${ }^{33}$ found no differences in the number of errors in sequencing of hands movement. All children in this study were right-handed and the tests were performed only with the right 
hand. Another approach of manual praxis and the sequencing of movements are to assess the kinetic and ideomotor ability of arms. The first was related to the fine motor skills for completion of tasks; the cortical location for this function is probably the motor cortex. The second, requiring more complex mechanisms including interpretative targeting involve cortical areas outside the rolandic region, such as the lower parietal lobe and supplementary motor area ${ }^{34}$. Several studies describe neuropsychological abnormalities in children with BECTS, among then the attention and the executive process failure play a crucial role ${ }^{35-38}$. The poor results found among children with BECTS when compared to the control group can be explained by the presence of focal interictal discharge in the perisylvian region during the "active period" of epilepsy (presence of focal discharge) which would be responsible for damage to the frontal lobe connections affecting the development of attentional control, confirming previous studies ${ }^{39,40}$ and this dysfunction would cause failure in school learning.

\section{ACKNOWLEDGMENT}

The authors thank all children and their families for the great collaboration and trust.

\section{References}

1. Wirrell EC. Benign epilepsy of childhood with centrotemporal spikes. Epilepsia 1998;39(Suppl 4):S32-S41.

2. Panayiotopoulos CP. Benign childhood epilepsy with centrotemporal spikes or Rolandic seizures. In: Panayiotopoulos CP. Benign childhood partial seizures and related epileptic syndrome. London, John Libbey \& Company Ltd, 1999. p. 33-70.

3. Heijbel J, Bohman M. Benign epilepsy of children with centrotemporal EEG foci: intelligence, behavior, and school adjustment. Epilepsia 1975;16:679-687.

4. Beaussart M. Benign epilepsy of children with Rolandic (centrotemporal) paroxysmal foci. A clinical entity. Study of 221 cases. Epilepsia 1972;13:795-811.

5. Loiseau P, Cohadon F, Montureux Y. A propos d'une forme singuliere d'epilepsie de l'enfant. Rev Neurol (Paris) 1967;116:244-248.

6. Lerman P, Kivity S. Focal epileptic EEG discharges in children not suffering from clinical epilepsy. Epilepsy Res Suppl 1992;6:99-103.

7. Lombroso CT. Sylvian seizures and midtemporal spikes foci in children. Arch Neurol 1967;17:52-59.

8. Blom S, Heijbel J, Bergfors PG. Benign epilepsy with centrotemporal foci: prevalence and follow-up study of 40 patients. Epilepsia 1972;13:609-619.

9. Bouma PAD, Bovenkerk AC, Westendorp RGJ, Brouwer O. The course of benign partial epilepsy of childhood with centrotemporal spikes: a meta-analysis. Neurology 1997;48:430-433.

10. Lüders H, Lesser R, Dinner D. Benign focal epilepsy of childhood. In: Lüders H, Lesser RP (ed.) Epilepsy: electroclinical syndromes. Berlin: Springer;1987. p. 303-346.

11. Piccirilli M, D'Alessandro P, Tiacci C, Ferroni A. Language lateralization in children with benign partial epilepsy. Epilepsia 1988;29:19-25.

12. Staden U, Isaacs E, Boyd SG, Brandl U, Neville BGR. Language dysfunction in children with Rolandic epilepsy. Neuropediatrics 1998;29:242-248.

13. Piccirilli M, D'Alessandro P, Sciarma T, et al. Attention problems in epilepsy: possible significance of the epileptogenic focus. Epilepsia 1994;35:1091-1096.

14. Massa R, Saint-Martin A, Carcangiu R, et al. EEG criteria predictive of complicated evolution in idiopathic rolandic epilepsy. Neurology 2001;57:1071-1079.

15. Deonna TW, Roulet E.; Fontan D, Marcoz JP. Speech and oromotor deficits of epileptic origin in benign partial epilepsy of childhood with rolandic spikes (BPERS). Relationship to the acquired aphasiaepilepsy syndromes. Neuropediatrics 1993;24:83-87.

16. Lerman P. Benign childhood epilepsy with centrotemporal spikes (BECT). In: Engel Jr. J, Pedley TA (eds.) Epilepsy: a comprehensive textbook. Philadelphia: Lippincott-Raven Publishers; 1997. p. 2307-2314.
17. Holmes GL, Wong PKH. Topographical analysis of the centrotemporal discharges in benign rolandic epilepsy of childhood. Epilepsia 1984:25:705-711.

18. Luria AR. Fundamentos de Neuropsicologia. Ricardo JA (trad.). São Paulo: Universidade de São Paulo; 1981. p. 5-26.

19. Roulet E, Deonna T, Despland PA. Prolonged intermittent drooling and oromotor dyspraxia in benign partial epilepsy of childhood epilepsy with centrotemporal spikes. Epilepsia 1989;30:564-568.

20. Laub MC, Funke R, Kirsch CM, Oberst U. BECT: comparison of cerebral blood flow imaging, neuropsychological testing and long-term EEG finding. Epilepsy Res Suppl 1992;6:95-98.

21. Sarikaya A, Kaya M, Karasalihoglu S, et al. Comparison between semiquantitative interictal Tc-99m HMPAO SPECT and clinical parameters in children with partial seizures. Brain Dev 1999; 21:179-183.

22. Duncan R. The clinical use of SPECT in focal epilepsy. Epilepsia 1997;38(Suppl 10):S39-S41.

23. Chan RCK, Rao H, Chen EEH, Ye B, Zhang C. The neural basis of motor sequencing: an fMRI study of healthy subjects. Neurosci Lett 2006;398:189-194.

24. Umetsu A, Okuda J, Fuji T, et al. Brain activation during the fist-edgepalm test: a functional MRI study. Neuroimage 2002;17:385-392.

25. Apollonio I, Leone M, Isella V, et al. The Frontal Assessment Battery (FAB): normative values in an Italian population sample. Neurol Sci 2005;26:108-116.

26. Ying $M$, Chen $B$, Tian $Y$, et al. Nuclear import of human sexual regulator DMRT1 is mediated by importin- $\beta$. Biochim Biophys Acta 2007;1773:804-813

27. Rizzolatti G, Fadiga L, Galesse V, Fogassi L. Premotor cortex and the recognition of motor actions. Brain Res Cogn Brain Res 1996;3:131-141.

28. Haaland $\mathrm{KY}$, Elsinger CL, Mayer AR, Durgerian S, Rao SM. Motor sequence complexity and performing hand produce differential patterns of hemispheric lateralization. J Cog Neurosci 2004;16:621-636.

29. Heiser M, lacoboni M, Maeda F, Marcus J, Mazziotta JC The essential role of Broca's area in imitation. Eur J Neurosci 2003; 17:1123-1128.

30. Nitrini R, Caramelli P, Herrera E Jr, Charchat-Fichman H, Porto CS Performance in Luria's fist-edge-palm test according to education level. Cog Behav Neurol 2005;18:211-214.

31. Dewey D. Error analysis of limb and orofacial praxis in children with developmental motor deficits. Brain Cogn 1993;23:203-221.

32. Binkofski F, Amunts K, Stephan KM, et al. Broca's region subserves imagery of motion: a combined cytoarchitectonic and fMRI study. Hum Brain Mapp 2000;11:273-285. 
33. Crary MA. Developmental motor speech disorders. Assessment strategies: a sense of perspective. California: San Diego; 1993. p. 171-198.

34. Caldas AC. A herança de Franz Joseph Gall: o cérebro ao serviço do comportamento humano. 3a ed. Lisboa: McGraw-Hill; 2000. p. 151-192.

35. Weglage J, Demsky A, Pietsch M, Kurlemann G. Neuropsychological, intellectual, and behavioral findings in patients with centrotemporal spikes with and without seizures. Dev Med Child Neurol 1997; 39:646-651.

36. Güdüz E, Demirbilek V, Korkmaz B. Benign rolandic epilepsy: neuropsychological findings. Seizure 1999;8:246-249.
37. Metz-Lutz MN, Filippini M. Neuropsychological finding in Rolandic epilepsy and Landau-Kleffner syndrome. Epilepsia 2006; 47(Suppl 2):71-75

38. Pinton F, Ducot B, Motte J, et al. Cognitive functions in children with benign childhood epilepsy with centrotemporal spikes (BECTS). Epileptic Disord 2006;8:11-23.

39. Deltour L, Barathon M, Quaglino V, et al. Children with benign epilepsy with centrotemporal spikes (BECTS) show impaired attentional control: evidence from an attentional captures paradigm. Epileptic Disord 2007;9:32-38.

40. Chevalier H, Metz-Lutz MN, Segalowitz SJ. Impulsivity and control of inhibition in Benign Focal Childhood Epilepsy (BFCE). Brain Cogn 2000;43:86-90. 